Article

\title{
The Arabidopsis Hypoxia Inducible AtR8 Long Non-Coding RNA also Contributes to Plant Defense and Root Elongation Coordinating with WRKY Genes under Low Levels of Salicylic Acid
}

\author{
Shuang $\mathrm{Li}^{1}$, Saraswati Nayar ${ }^{2,+}$, HuiYuan Jia ${ }^{1}$, Sanjay Kapoor ${ }^{2}{ }^{\mathbb{D}}$, Juan $\mathrm{Wu}^{3}$ and \\ Yasushi Yukawa ${ }^{1, *}$ \\ 1 Graduate School of Science, Nagoya City University, Nagoya 467-8501, Japan; s.ri@nsc.nagoya-cu.ac.jp (S.L.); \\ jia@nsc.nagoya-cu.ac.jp (H.J.) \\ 2 Department of Plant Molecular Biology, University of Delhi South Campus, Benito Juarez Road, \\ New Delhi 110021, India; saraswatin@rgcb.res.in (S.N.); kapoors@genomeindia.org (S.K.) \\ 3 Key Laboratory of Saline-Alkali Vegetation Ecology Restoration, Ministry of Education, College of Life \\ Science, Northeast Forestry University, Harbin 150040, China; wuj1970@163.com \\ * Correspondence: yyuk@nsc.nagoya-cu.ac.jp \\ † Present address: DST-INSPIRE Faculty, Rajiv Gandhi Centre for Biotechnology, Trivandrum 695014, India.
}

Received: 16 January 2020; Accepted: 23 February 2020; Published: 26 February 2020

check for updates

\begin{abstract}
AtR8 lncRNA was previously identified in the flowering plant Arabidopsis thaliana as an abundant Pol III-transcribed long non-coding RNA (lncRNA) of approximately $260 \mathrm{nt}$. AtR8 lncRNA accumulation is responsive to hypoxic stress and salicylic acid (SA) treatment in roots, but its function has not yet been identified. In this study, microarray analysis of an atr8 mutant and wild-type Arabidopsis indicated a strong association of AtR 8 lncRNA with the defense response. AtR8 accumulation exhibited an inverse correlation with an accumulation of two WRKY genes (WRKY53/WRKY70) when plants were exposed to exogenous low SA concentrations ( $20 \mu \mathrm{M})$, infected with Pseudomonas syringae, or in the early stage of development. The highest AtR8 accumulation was observed 5 days after germination, at which time no WRKY53 or WRKY70 mRNA was detectable. The presence of low levels of SA resulted in a significant reduction of root length in atr8 seedlings, whereas wrky53 and wrky70 mutants exhibited the opposite phenotype. Taken together, AtR8 lncRNA participates in Pathogenesis-Related Proteins 1 (PR-1)-independent defense and root elongation, which are related to the SA response. The mutual regulation of AtR8 $\operatorname{lncRNA}$ and WRKY53/WRKY70 is mediated by Nonexpressor of Pathogenesis-Related Gene 1 (NPR1).
\end{abstract}

Keywords: Arabidopsis; AtR8 lncRNA; defense; long non-coding RNA; NPR1; PR-1; Pseudomonas syringae; root elongation; salicylic acid; WRKY

\section{Introduction}

Non-coding RNA (ncRNA) generally refers to transcripts that do not encode proteins, and such RNAs are widely encountered in organisms. The large-scale systematic annotation and functional characterization studies of genes available in the ENCODE and FANTOM databases report that at least $80 \%$ of mammalian genomic DNA is actively transcribed into huge numbers of ncRNAs [1,2]. For plants, a genome-wide search for ncRNAs has been previously performed in a variety of plants such as Arabidopsis thaliana, Medicago truncatula, and so on [3]. These can be classified into two groups according to length: small ncRNAs (sncRNAs) and long ncRNAs (lncRNAs). SncRNAs are $<200 \mathrm{nt}$ in length and thus encompass micro RNAs (miRNA; approximately $22 \mathrm{nt}$ ), small interfering RNAs (siRNA; 20-25 nt) 
and related ncRNAs (piRNA, natsiRNA, and ta-siRNA; 21-30 nt), 5S rRNA (approximately $120 \mathrm{nt}$ ), and tRNAs (75-95 nt). Small nuclear RNAs (snRNA) and small nucleolar RNAs (snoRNA) are also classified as sncRNAs.

By contrast, lncRNAs are $\geq 200 \mathrm{nt}$ in length. Plant lncRNAs play roles in responses to biotic and abiotic stress [4-6]. For example, 125 lncRNAs involved in powdery mildew infection and high-temperature stress have been identified in wheat during responses to biotic stress [7]. After exposure of Arabidopsis thaliana to drought, cold, high salt, or abscisic acid, the expression of 1832 IncRNAs was up-regulated markedly when compared with the control group [8]. More recently, genome-wide studies showed that IncRNAs respond to heat and salt stress in Chinese cabbage (Brassica rapa) and poplar (Populus trichocarpa), respectively [9,10].

Several lncRNAs have been identified and functionally characterized in plants [11-15]. The plant lncRNAs identified to date are mainly transcribed by RNA polymerase II (Pol II). In addition, a small number of plant lncRNAs have been identified that are transcribed by other RNA polymerases. These include 7-2/MRP RNA, U3 snoRNA, and SINE RNAs, which are transcribed by RNA polymerase III (Pol III), and scaffold lncRNAs for Argonaute binding to chromatin, which are transcribed by RNA polymerase V (Pol V) in Arabidopsis [16].

AtR8 IncRNA in Arabidopsis was identified by in silico prediction and subsequently validated as an approximately $260 \mathrm{nt}$ transcript by in vitro transcription assays involving Pol III activity in tobacco nuclear extracts [17]. AtR 8 transcription is responsive to hypoxic stress and SA treatment, and the AtR 8 lncRNA is expressed in relative abundance in the root tips of seedlings and cytosol of Arabidopsis MM2d cultured cells. AtR8 lncRNA is conserved in six additional taxa of Brassicaceae, and the secondary structure of these RNAs is also conserved across the six taxa [17]. The closest homolog of AtR8 lncRNA (BoNR8 lncRNA) found in cabbage (Brassica oleracea) affected seed germination and growth [18]. Unlike pre-miRNAs or ENOD40 transcripts [19], AtR8 IncRNA was not processed into a smaller fragment, and a short open reading frame was not found in the transcribed region.

Plants are sessile organisms and are thus constantly exposed to a wide range of environmental abiotic and biotic stressors. Therefore, plants have evolved several active defense/response mechanisms to withstand adverse environmental conditions. Salicylic acid (SA) is a phytohormone and an endogenous signaling molecule that affects physiological processes such as development, photosynthesis, transpiration, ion uptake/transport, and response to stress. SA also induces specific morphological changes in the structures of leaves, roots [20], and chloroplasts. Significantly, SA signaling in plants plays a major role in mediating defense responses against microbial pathogens and herbivores [21].

Flowering plants contain many regulators in the SA signaling cascade and, among these, WRKY transcription factors (TFs) play roles of pivotal importance. The regulatory pathways of WRKY TFs are involved in the response to biotic and abiotic stresses [22,23]. WRKYs represent one of the largest families of TFs in plants. For example, Arabidopsis contains 74 WRKY genes, which have been divided into three groups (I-III) based on the number of WRKY domains and the structure of the zinc-finger motifs in their encoded proteins. Group I members contain two WRKY domains and a $\mathrm{C}_{2} \mathrm{H}_{2}$-type zinc-finger motif, group II members contain one WRKY domain and a $\mathrm{C}_{2} \mathrm{H}_{2}$-type zinc-finger motif, and group III members contain one WRKY domain and a $\mathrm{C}_{2} \mathrm{HC}$-type zinc-finger motif [24]. AtWRKY54 and AtWRKY70, which belong to group II, have been implicated in the response to biotic stress and the orchestration of SA and jasmonic acid (JA) signaling pathways during plant defense [25-27]. AtWRKY22 responds to both defense and hypoxia [28]. AtWRKY54 and AtWRKY70 act cooperatively as negative regulators of leaf senescence, which is a prolonged type of programmed cell death $[29,30]$. AtWRKY53 is also a key player in age-induced leaf senescence [31-34]. Finally, AtWRKY46, together with AtWRKY54 and AtWRKY70, coordinates basal resistance against the plant pathogen Pseudomonas syringae (P. syringae) [35]. WRKY and PR genes, which encode Pathogenesis-Related Proteins such as PR-1, contain a conserved 'W-box' as a cis element and are 
regulated by Nonexpressor of Pathogenesis-Related Gene 1 (NPR1), which is a master regulator of SA-dependent plant immunity $[26,36]$.

In this study, a microarray-based transcriptome analysis of an AtR 8 lncRNA-defective mutant (atr8) under hypoxic stress revealed a tight interaction between AtR 8 lncRNA and defense functions, which were induced by low-level SA. To further understand the potential defensive role of AtR8 lncRNA, relationships between AtR8 and WRKY53/WRKY70 in the presence of SA or upon infection with $P$. syringae were also examined. Futhermore, AtR 8 lncRNA was also involved in root elongation under low SA concentrations $(20 \mu \mathrm{M})$. Therefore, this study proposes the importance of AtR 8 lncRNA in the post-germination development of early seedlings, which is likely to relate to defense functions in the early developmental stage of plants.

\section{Results}

2.1. Correlation between Transcription of AtR8 IncRNA and WRKY TF Genes in Arabidopsis Seedlings under Hypoxic Stress

AtR8 lncRNA responds to hypoxic stress and SA treatment [17]. To further understand its function, a microarray-based differential expression analysis was performed between AtR 8 lncRNA-gene defective null mutant (atr8; obtained from the Salk library) and wild-type (Wt) Arabidopsis seedlings. Ten-day-old Wt and atr 8 seedlings were subjected to hypoxic conditions for $6 \mathrm{~h}$ and then allowed to recover for $22 \mathrm{~h}$ under normal conditions, as previously described [17]. Total RNA was extracted from treated atr 8 and $\mathrm{Wt}$ seedlings and subjected to transcriptomic analysis using the Affymetrix GeneChip platform.

In total, 434 genes were differentially expressed ( $\geq 2$-fold change; $p \leq 0.05$ ) between $\mathrm{Wt}$ and atr8. Of these, 145 genes were down-regulated and 289 were up-regulated in atr 8 compared with Wt (Supplemental Table S2). Differentially expressed genes were annotated based on gene ontologies (Supplemental Tables S4 and S5) and subjected to hypergeometric distribution tests for both up- and down-regulated genes. The top 15 down-regulated categories are shown in Figure 1A, and a complete list is provided in Supplemental Table S3. Genes involved in cellular biosynthetic processes such as photosynthesis, light response, and carbohydrate synthesis were down-regulated. The Arabidopsis Information Resources (TAIR) Gene Ontology (GO) analysis [37] of down-regulated genes annotated 11 gene products as metabolic process, 10 as nuclear, 13 as plastidic, and five as mitochondrial components (Supplemental Tables S4 and S5). By contrast, a large proportion of up-regulated genes was found to be related to the stress response and defense (Figure 1A, lower panel). TAIR GO annotation analysis revealed that among the up-regulated genes, 26 were categorized as stress responsive and 20 were responsive to abiotic or biotic stimuli, while 14 up-regulated genes were associated with plasma membranes and five were associated with cell wall components. The first obstacle encountered by a pathogen is the plant cell wall; thus, membrane trafficking is key to establishing a rapid defense response $[38,39]$. Ten up-regulated genes encoded kinases, and eight encoded signal transduction components that may participate in stress responses and defense. In total, GO annotations associated at least 122 of the 434 differentially expressed genes with one or more kinds of stress or defense-related function (Supplemental Table S6). Of these 122 genes, 104 were up-regulated in atr 8 compared with $\mathrm{Wt}$. Thus, a large proportion (36\%) of the 289 genes up-regulated in atr 8 were associated with stress- or defense-related functions (Supplemental Tables S5 and S6). 
A Down regulated in atr8 (65 genes)

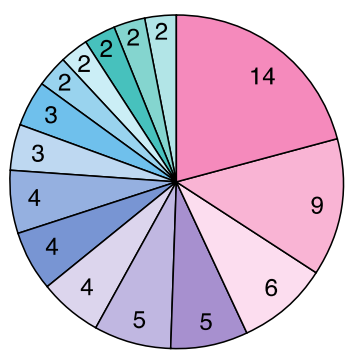

Up regulated in atr8 (169 genes)

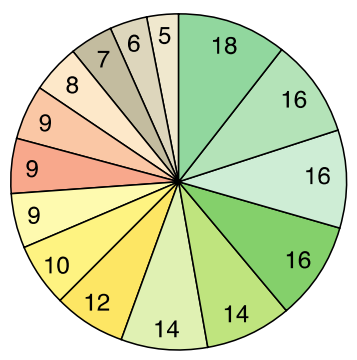

Photosynthesis

Photosynthesis, light harvesting

Cellular cell wall organization

Cellular glucan metabolic process

Response to red light

Cold acclimation

Response to blue light

Response to far red light

Photosystem II stabilization

Protein-chromophore linkage

Regulation of protein dephosphorylation

Photosystem II assembly

Glucosinolate catabolic process

Photoinhibition

Photosynthesis, light reaction

Defense response

Response to chitin

Defense response to bacterium

Protein phosphorylation

Defense response to fungus

Response to oxidative stress

Oxidation reduction

Response to bacterium

Response to jasmonic acid stimulus

Response to wounding

Response to salt stress

Hydrogen peroxide catabolic process

Response to salicylic acid stimulus

Defense response to bacterium,

compatible interaction

Regulation of defense response
B

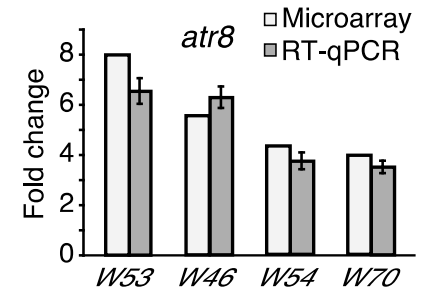

C
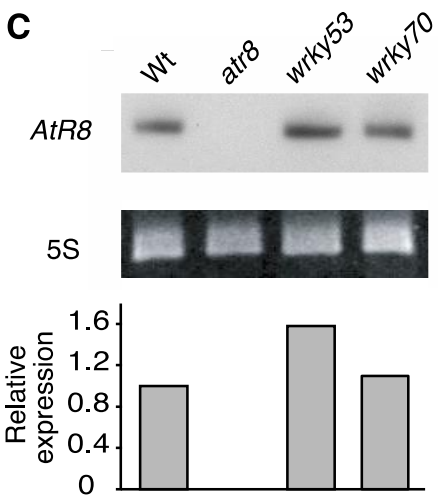

Figure 1. Microarray analysis and WRKY genes accumulation in atr8 mutant. (A) Microarray analysis using the total RNAs from atr8 and wild-type (Wt) in combination with Affimetrix GeneChip (ATH1 Arabidopsis expression array). Function categories of down- and up-regulated genes were obtained by a hypergeometric distribution test (cf. Supplemental Table S2). Each of the top 15 categories are shown on a pie chart with the number of genes classified. (B) Comparison of WRKY transcription factor (TF) gene accumulation in atr 8 mutant dipped in water for $6 \mathrm{~h}$ and then recovered for $24 \mathrm{~h}$. These mRNA accumulation levels were determined by GeneChip and RT-qPCR with the same RNA samples, while ACT2 and ACT8 genes were used as standards for RT-qPCR. Bar graphs represent the mean values of three independent assays, and the error bars represent \pm SE. W53: WRKY53, W46: WRKY46, W54: WRKY54, and W70: WRKY70. (C) RNA gel blot analysis showing the basal expression of AtR8 IncRNA in Wt as well as the atr8, wrky53, and wrky70 mutant treated with water as (A). The quantification of the gel blot was made using ImageJ.

Included in the 289 genes that were up-regulated in the atr 8 mutant line were 12 WRKY-class TF-encoding genes (Table 1). To date, 74 WRKY genes have been identified in Arabidopsis, indicating that one in six WRKY genes were affected by the atr8 mutation. WRKY TFs are involved in biotic and abiotic stress responses as well as senescence, seed dormancy, seed germination, several developmental processes, and submergence responses [22]. The up-regulation of WRKY53, WRKY46, WRKY54, and WRKY70 transcription in atr8 was validated by reverse transcription quantitative PCR (RT-qPCR), and the results were consistent with those obtained from the microarray analysis (Figure 1B). From these results, it can be inferred that hypoxia induces AtR 8 lncRNA participation in the plant defense system, including WRKY cascade. In addition, RNA gel blot analysis using Wt, atr8, wrky53, and wrky70 mutants growing in non-stressed condition showed that AtR8 lncRNA was not detectable in atr8 plants and increasing in wrky53 plants (Figure 1C). Two relatively well-studied WRKY genes, WRKY53 and WRKY70, exhibited approximately 8- and 4-fold up-regulation, respectively, and they were thus selected for detailed functional characterization to further understand the role of AtR8 in the stress response. 
Table 1. WRKY transcription factor genes that exhibit a more than 2-fold change in atr8.

\begin{tabular}{ccccc}
\hline TAIR ID & Fold Change & Regulation & Expression Level & Gene Title \\
\hline AT1G80840 & 9.87 & up & 1137.8 & WRKY40 \\
AT4G23810 & 7.95 & up & 1595.3 & WRKY53 \\
AT2G46400 & 5.52 & up & 786.6 & WRKY46 \\
AT5G22570 & 5.03 & up & 211.4 & WRKY38 \\
AT2G40750 & 4.31 & up & 1474.1 & WRKY54 \\
AT5G13080 & 4.14 & up & 464.9 & WRKY75 \\
AT3G56400 & 3.94 & up & 3225.8 & WRKY70 \\
AT2G38470 & 3.39 & up & 1878.9 & WRKY33 \\
AT5G49520 & 3.08 & up & 475.3 & WRKY48 \\
AT2G25000 & 2.21 & up & 784.7 & WRKY60 \\
AT1G66550 & 2.04 & up & 9.4 & WRKY67 \\
AT4G31550 & 2.04 & up & 1212.9 & WRKY11 \\
\hline
\end{tabular}

\subsection{Impact of $S A$ Exposure in atr8 and wrky Mutants on Root Elongation}

Previously, we reported that $A t R 8 \operatorname{lncRNA}$ accumulated in the primary root apices and that its accumulation was affected by treatment with SA [17]. When Arabidopsis seedlings were treated for $18 \mathrm{~h}$ with $0.5 \mathrm{mM} \mathrm{SA}$ and then subjected to recovery treatment (no SA, $48 \mathrm{~h}$ ), AtR 8 lncRNA accumulation decreased to almost half of the original control levels [17]. The effect of exogenous SA application on vegetative growth is not universal, being dependent on plant species and SA concentration [21]. Although the effect of exogenous SA application on vegetative growth is dependent on plant species and SA concentration [21], we performed comparisons of the root lengths of $\mathrm{Wt}$, atr8, wrky53, and wrky70 seedlings in the presence of different concentrations because it provides a simple and effective method to assess the effect of SA. Clear differential inhibitory effects on root elongation were observed only in a narrow window of low SA concentrations ( $20 \mu \mathrm{M}$; Figure 2, Supplemental Figures S1 and S2). The inclusion of $20 \mu \mathrm{M} \mathrm{SA}$ (SA ${ }^{\text {plus }}$ ) resulted in diminished root elongation in $\mathrm{Wt}$ and further reduction of root length in atr8 seedlings. However, in SA-free media (SA ${ }^{\text {minus}}$ ), the root lengths of atr8, wrky53, and wrky 70 were similar to those of Wt. The differential effect between $\mathrm{Wt}$ and atr 8 was not observed at higher SA levels ( $25 \mu \mathrm{M}$ or $10 \mathrm{mM} \mathrm{SA}$ ) (Supplemental Figure S1). By contrast, the wrky53 and wrky70 mutant lines exhibited longer roots than those of $\mathrm{Wt}$ in $\mathrm{SA}^{\text {plus }}$ (Figure 2). The results showed that there was a certain correlation between AtR8 IncRNA and WRKY53 and WRKY70 under the condition of low concentration of SA, and this correlation indicated that AtR8 lncRNA might have an antagonistic relationship with these two WRKY proteins in an SA-dependent inhibition of primary root elongation.

With respect to root elongation, the primary roots of the shr mutant are especially short [40]. Arabidopsis SHR and its related SCARECROW (SCR) gene, a key regulator of radial patterning and stem cell niche specification in roots [41], have been well characterized. The mutation of SHR and SCR genes causes a disorganization of the quiescent center in root apical meristems (RAM) and loss of the maintenance activity of peripheral stem cells, leading to a short-root phenotype [42-44]. RT-qPCR analysis indicated that SHR mRNA accumulation was up-regulated in both Wt and atr 8 under SAplus conditions (Figure 3), and prominent accumulation was observed in the atr 8 mutant 5 days after germination (DAG). 

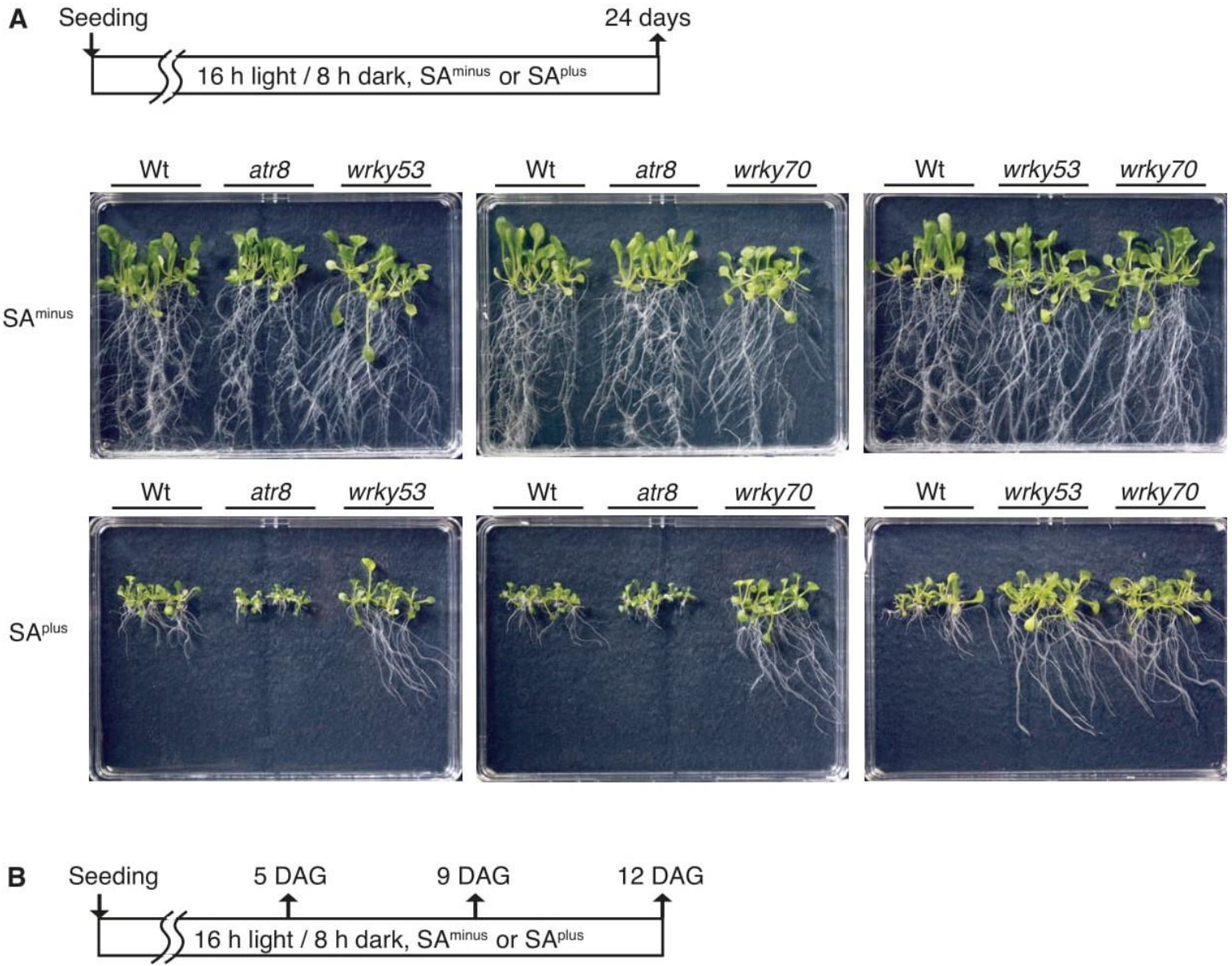

口Wt atr8 wrky53 wrky70
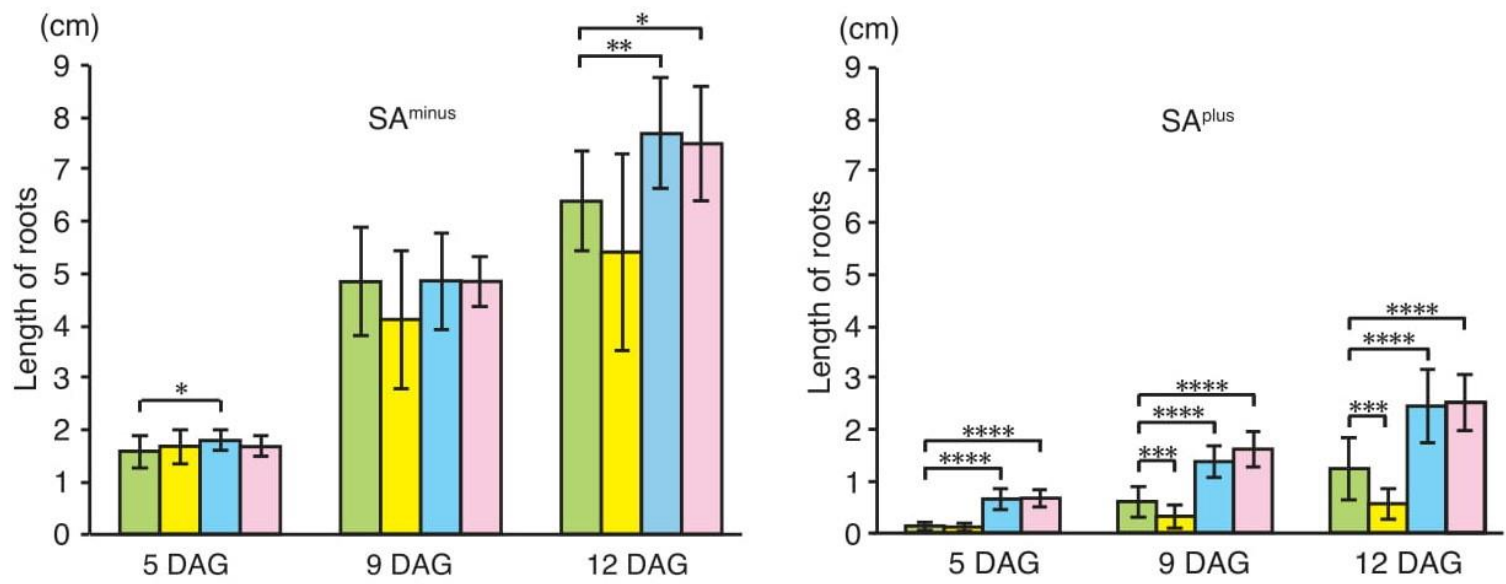

Figure 2. Inhibitory effects on the root elongation under lower salicylic acid (SA) conditions. (A) The root elongations of Arabidopsis seedlings were compared, which were grown on vertical $0.24 \%$ gellan gum medium with (SA ${ }^{\text {plus }}$ ) or without (SA ${ }^{\text {minus }}$ ) $20 \mu \mathrm{M} \mathrm{SA}$ for 24 days after seeding. To eliminate gellan gum plate-dependent difference, $\mathrm{Wt}$ and two out of the three mutant plants were combined with three individual plates. (B) The lengths of the primary root of (Supplemental Figure S2) was measured using ImageJ. Seedlings were grown (A) and root lengths were compared at 5, 9, and 12 days after germination (DAG). Bar graphs represent the mean values of more than 10 plants, and error bars represent \pm SD. Significant differences in the lengths of the primary root between $\mathrm{Wt}$ and each of the mutants are indicated as ${ }^{*} p<0.05,{ }^{* *} p<0.01,{ }^{* * *} p<0.001$, and ${ }^{* * * *} p<0.0001$ (Welch's $t$-test). 
A

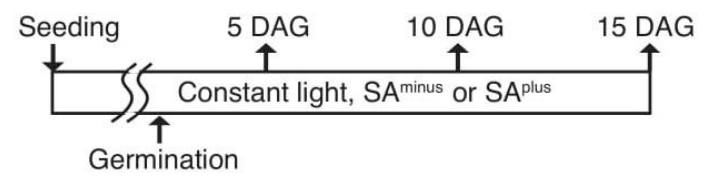

B

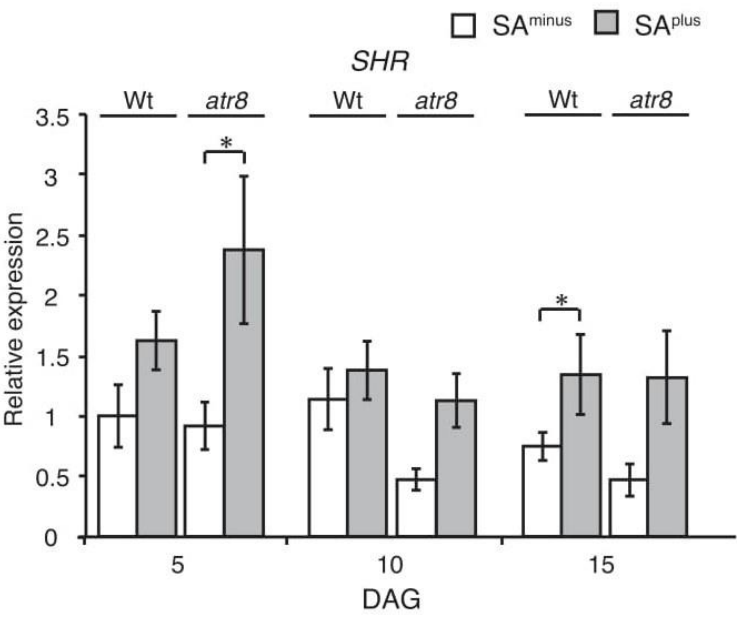

Figure 3. Accumulation levels of $S H R$ mRNAs in $\mathrm{Wt}$ and atr8 plants soon after germination. (A) Timeline of experimental procedure. Up arrows indicate samplings. (B) Time course of SHR mRNA accumulations. Arabidopsis seedlings that were grown on vertical $0.24 \%$ gellan gum media with (SA ${ }^{\text {plus }}$ ) or without (SA $\left.{ }^{\text {minus }}\right) 20 \mu \mathrm{M}$ salicylic acid, and total RNAs were extracted at 5, 10, and 15 days after germination (DAG), and subjected to RT-qPCR with ACT2 and ACT8 genes as standards. Bar graphs represent the mean values of three independent assays, and the error bars represent \pm SE. Significant differences in RNA accumulation levels between $\mathrm{SA}^{\text {minus }}$ and SA ${ }^{\text {plus }}$ are indicated as * $p<0.05$ (Welch's $t$-test).

\subsection{Long-Term SA Treatment and Gene Responses}

To study the relationship between $A t R 8$ lncRNA and the SA response in detail, the accumulation of AtR8, WRKY53, WRKY70, defense-related NPR1, and PR-1 transcripts was assayed in Wt, atr8, wrky53, and wrky70 backgrounds by RT-qPCR. Upon continuous SA plus treatment for 24 days after seeding, accumulation of the two WRKYs, NPR1, and PR-1 was induced in Wt, whereas AtR8 was repressed (Figure 4B). When atr 8 mutants were grown under SA ${ }^{\text {plus }}$ conditions, WRKY53, WRKY70, and NPR1 transcripts accumulated to higher levels than in $\mathrm{Wt}$, leading to further induction of the NPR1-dependent PR-1 gene (Figure 4C). In the wrky53 mutant, AtR8 lncRNA levels were slightly induced under SA plus conditions (Figure 4D), whereas the WRKY70, NPR1, and PR-1 mRNA levels were similar to those in $\mathrm{Wt}$, regardless of the SA conditions. The wrky70 mutants showed not statistically significant but faint induction of AtR 8 lncRNA under continuous SAplus/minus conditions. However, the SA-mediated induction in WRKY53 mRNA accumulation was lost in the wrky70 mutants (Figure 4E). This suggests that SA influences WRKY53 transcript levels via WRKY70. Furthermore, mutations in WRKY53 or WRKY70 led to an induction of AtR8 lncRNA accumulation, but it had no apparent effect on the transcript levels of NPR1 or PR-1. These results suggest that PR-1 accumulation was independent of AtR8 accumulation, which means that the AtR 8 lncRNA might participate in an unknown PR protein-independent defense mechanism. 

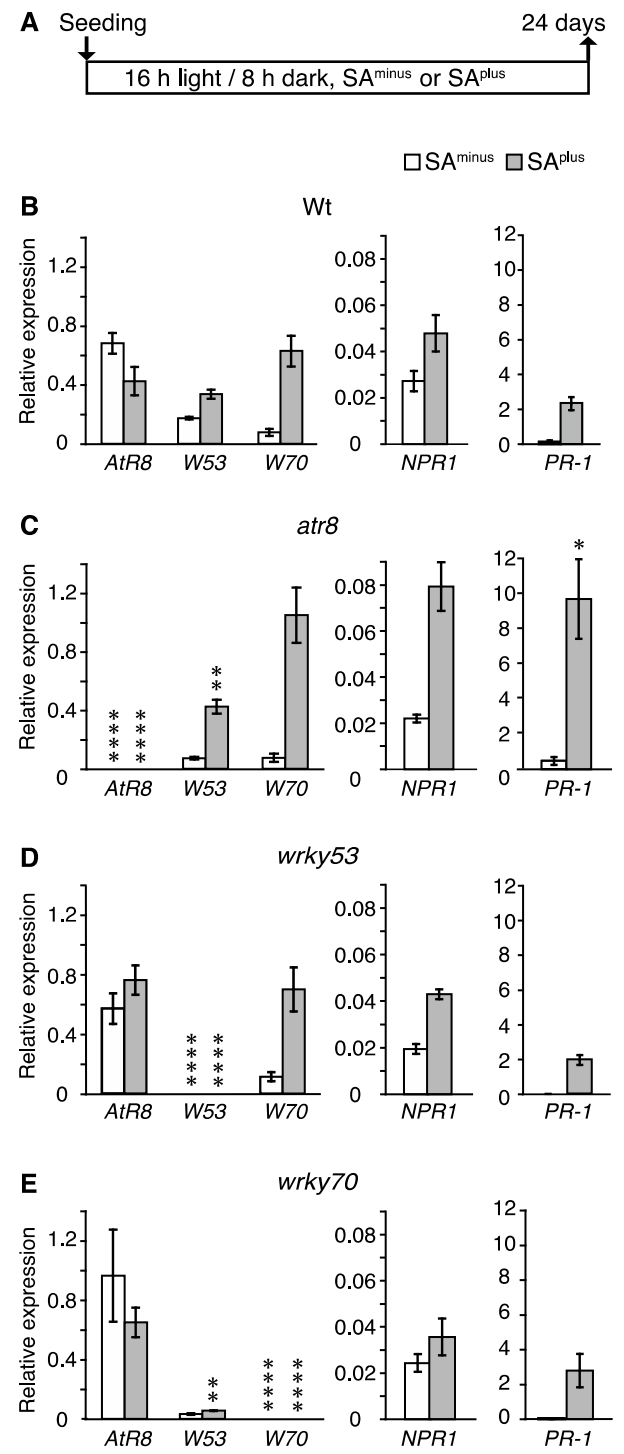

Figure 4. Accumulation levels of RNAs in Arabidopsis under continuous treatment with $20 \mu \mathrm{M}$ SA. (A) Timeline of experimental procedure. Up arrow indicates sampling. The total RNAs were extracted from the same seedlings shown in Supplemental Figure S2 (24 days after seeding). (B-E) The mRNA accumulation levels $\mathrm{SA}^{\text {minus }}$ or SA ${ }^{\text {plus }}$ were compared by RT-qPCR with ACT2 and ACT8 genes as standards. Bar graphs represent mean values of three independent assays ( $\geq 50$ plants), and error bars represent \pm SE. W53: WRKY53, W70: WRKY70. Significant differences in RNA accumulation levels between Wt (B) and each of the mutants (C-E) are indicated as ${ }^{*} p<0.05,{ }^{* *} p<0.01$ and ${ }^{* * * *} p<0.0001$ (Welch's $t$-test).

\subsection{Effects of Short-Term SA Treatment on Gene Responses}

Time-course experiments were conducted to precisely determine the short-term induction effects of SA on the accumulation of individual genes. Two-week-old $\mathrm{Wt}$, atr8, wrky53, and wrky70 seedlings were dipped once into a $20 \mu \mathrm{M}$ SA solution and incubated on fresh $\frac{1}{2}$ Murashige and Skoog (MS) agar plates with $20 \mu \mathrm{M}$ SA for 0-24 h. RT-qPCR analysis showed that WRKY53 and WRKY70 mRNA levels in $\mathrm{Wt}$ increased rapidly in response to SA (after $1 \mathrm{~h}$ ) and then decreased gradually (Figure 5F). In the atr8 mutant, the WRKY70 mRNA accumulation pattern was similar to that of $\mathrm{Wt}$, whereas the increase in WRKY53 mRNA levels was less pronounced in atr8 than in Wt (Figure 5F,G). In the wrky53 mutant, AtR 8 lncRNA levels increased gradually to more than 2 -fold after $6 \mathrm{~h}$ in response to SA, and then declined to approximately $60 \%$ of their peak levels after $24 \mathrm{~h}$. The accumulation of WRKY70 mRNA 
was induced markedly $1 \mathrm{~h}$ after SA treatment (Figure 5F,H). In the wrky70 mutant, AtR 8 lncRNA was induced immediately after the SA treatment, whereas the pattern of WRKY53 mRNA accumulation was similar to that in the Wt (Figure 5F,I). These results indicate that WRKY53 or WRKY70 act as repressors in the SA-mediated regulation of AtR8 in the short-term presence of SA, and the responses of WRKY53 and WRKY70 genes under low-level SA are relatively rapid (start within one hour) and further induced in the atr8 mutant.
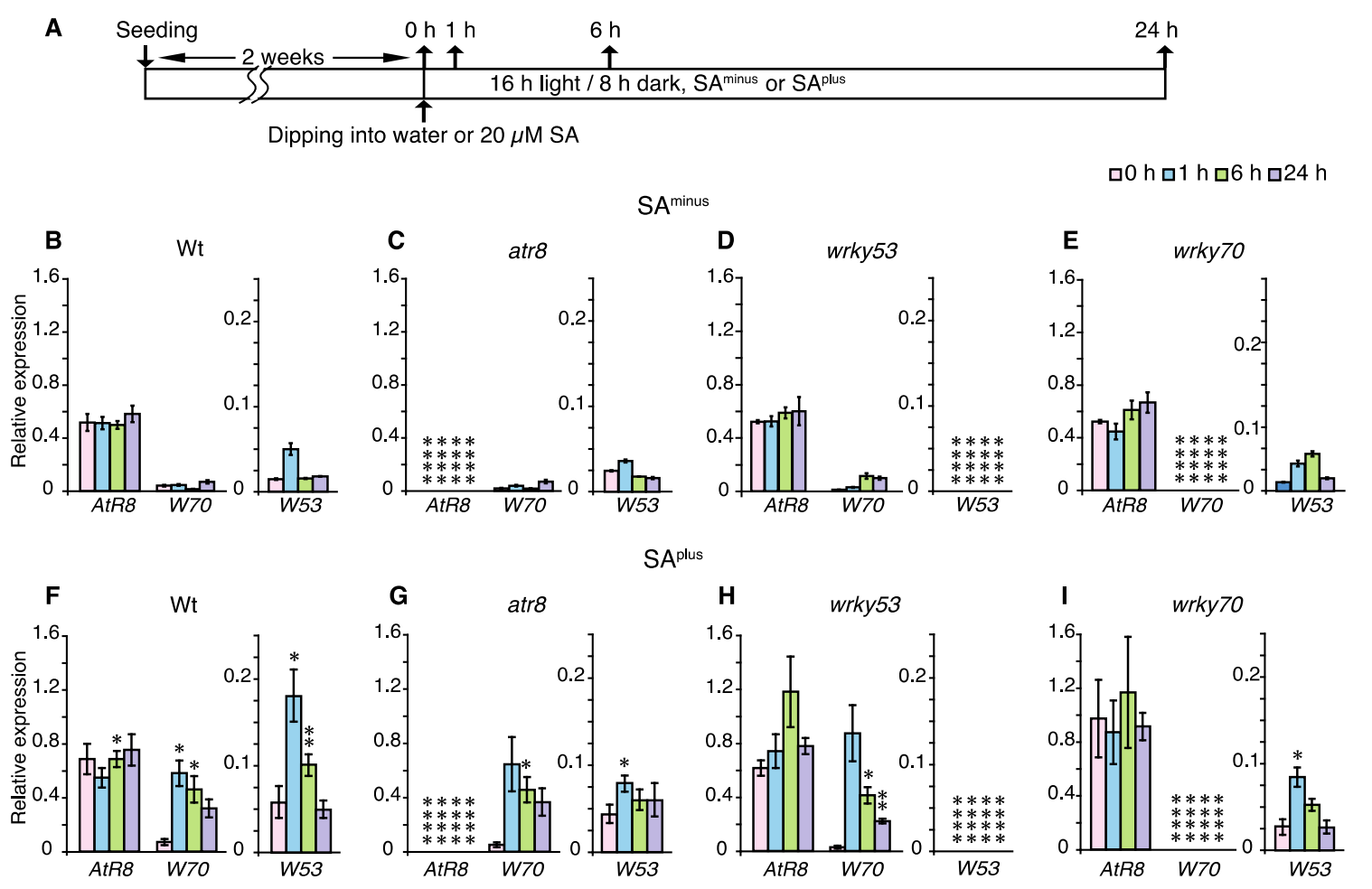

Figure 5. Short-term time course of RNA accumulation immediately after treatment with SA. (A) Timeline of experimental procedure with (SA ${ }^{\text {plus }}$ ) or without ( $\left.\mathrm{SA}^{\text {minus }}\right) 20 \mu \mathrm{M}$ salicylic acid. Two-week-old seedlings were dipped once into the water or $20 \mu \mathrm{M} \mathrm{SA}$ and incubated on fresh media (SA ${ }^{\text {minus }}$ or SA ${ }^{\text {plus }}$ ). Up arrows indicate samplings. Accumulations of AtR8 lncRNA as well as WRKY53 and WRKY70 mRNA in Arabidopsis plants were measured by RT-qPCR with ACT2 and ACT8 genes as standards. (B-E) Controls that were treated with just water (SA $\left.{ }^{\text {minus }}\right)$. (F-I) Seedlings treated with $20 \mu \mathrm{M}$ SA (SA ${ }^{\text {plus }}$ ). Bar graphs represent mean values of three independent assays ( $\geq 50$ plants), and error bars represent \pm SE. W53: WRKY53, W70: WRKY70. Significant differences in RNA accumulations levels between the same strain SA ${ }^{\text {minus }}$ and SAplus (Wt: B and F, atr8: C and G, wrky53: D and H, and wrky70: E and I) are indicated as ${ }^{*} p<0.05,{ }^{* *} p<0.01$ and ${ }^{* * * *} p<0.0001$ (Welch's $t$-test).

\subsection{Rapid Induction of WRKY and AtR8 Gene Expression by Pseudomonas syringae}

To understand the functional relevance of the interactions between AtR8 lncRNA and the two WRKY proteins as well as their subsequent involvement in the defense response, the responses of Wt and atr8, wrky53, and wrky70 mutants upon infection with the plant pathogen Pseudomonas syringae were analyzed. Two-week-old seedlings were infected with P. syringae and transferred to fresh SA-free $\frac{1}{2}$ MS agar plates. The $P$. syringae strain used in this study did not cause a hypersensitive response (HR) in Arabidopsis. Total RNA was extracted at 0, 0.5, 1, 6, 24, and $48 \mathrm{~h}$ after infection and subjected to RT-qPCR. Wt and wrky70 plants did not show any significant change in AtR 8 transcript accumulation upon infection (Figure 6B,E as well as Supplemental Figure S3). However, in the wrky53 plants, AtR8 lncRNA levels increased nearly 3 -fold at $6 \mathrm{~h}$ after infection, followed by gradual decrement (Figure $6 \mathrm{D}$ and Supplemental Figure S3). In all plants, WRKY53 and WRKY70 transcription was induced rapidly 30 min after infection, followed by rapid decline (Figure 6 and Supplemental Figure S3). This was 
particularly apparent in wrky 70 plants, where WRKY 53 transcript levels increased approximately 5 -fold upon infection (Figure 6E and Supplemental Figure S3). Therefore, WRKY53 might play a potentially pivotal role in mediating plant defense processes during the early stages of pathogen infection and act to repress AtR8 accumulation. Overall, the WRKY53 and WRKY70 responses to infection were fast and pronounced, whereas $A t R 8$ responses (both increase and decrease) were delayed. These results indicate that the AtR 8 lncRNA surely acts on plant defense cooperating with the WRKYs-PR-1 pathway.

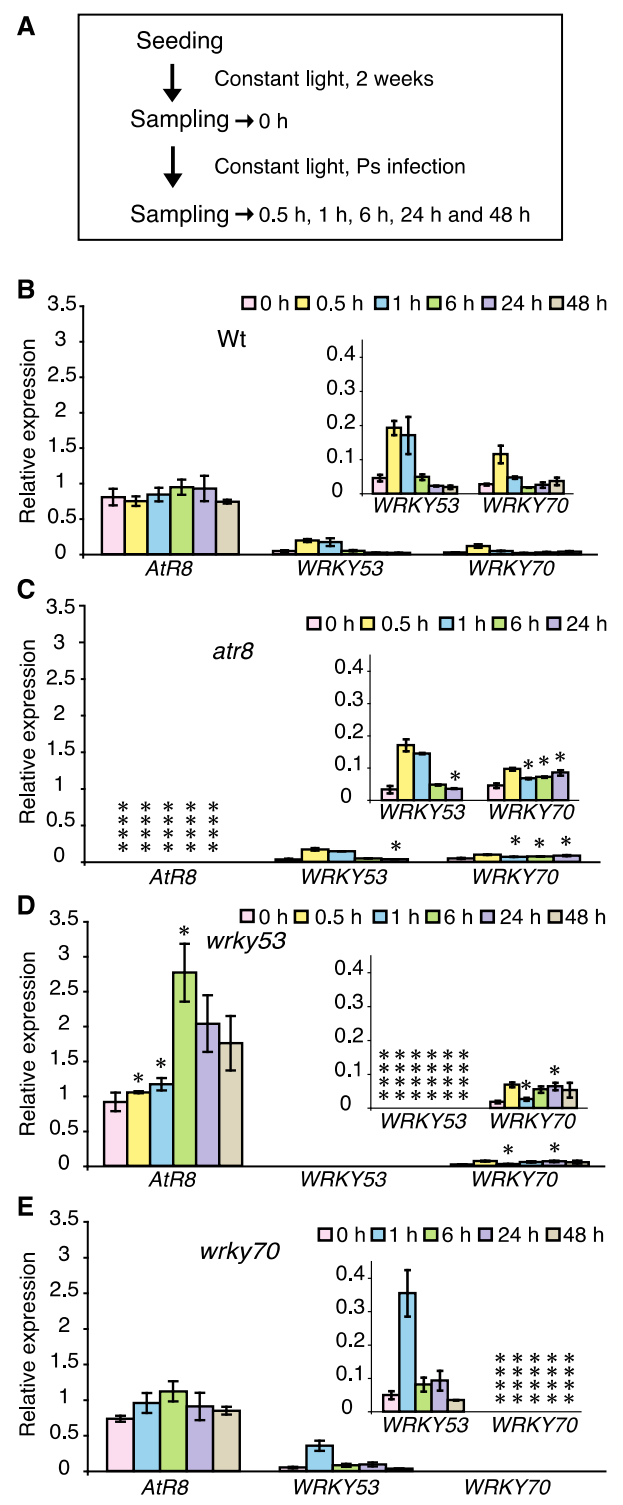

Figure 6. Short-term change of RNA levels by infection of plant pathogen Pseudomonas syringae (Ps). (A) Timeline of experimental procedure. AtR8 lncRNA, WRKY53, and WRKY70 in Arabidopsis plants were treated with Ps, which was cultured with $500 \mu \mathrm{l}$ of King's liquid medium and suspended in $50 \mathrm{~mL}$ of sterile water (100 times dilution). RNA accumulation levels of AtR8 lncRNA, WRKY53, and WRKY70 mRNAs with Ps were compared by RT-qPCR with ACT2 and ACT8 genes as standards. Bar graphs represent the mean values of three independent assays (more than 50 plants), and error bars represent \pm SE. The $X$-axis magnified bar graphs are superimposed in each graph. Significant differences in RNA accumulations levels between Wt (B) and each of the mutants (C-E) are indicated as * $p<0.05$ and ${ }^{* * * *} p<0.0001$ (Welch's $t$-test). 


\subsection{Temporal Accumulation of RNAs after Germination}

Our recent study showed that a homolog of $A t R 8 \operatorname{lncRNA}$ in cabbage (BoNR8 $\operatorname{lncRNA}$ ) affects seed germination and growth, and that its accumulation peaks $24-48 \mathrm{~h}$ after germination [18]. To determine whether the accumulation of AtR8 IncRNA was temporally regulated in Arabidopsis, we performed a post-germination time-course analysis. $\mathrm{Wt}$, atr8, and wrky70 seeds were germinated on SA-free gellan gum gel media, and total RNAs were extracted 5, 10, and 15 DAG and subjected to RT-qPCR. As shown in Figure 7, AtR8 lncRNA levels peaked 5 DAG and then declined gradually toward 15 DAG in both Wt and wrky70 plants. However, the rate of decrease was lower in the wrky70 line than in Wt. Conversely, WRKY53 and WRKY70 transcripts were almost undetectable 5 DAG in all plants. However, their levels increased gradually, which was concomitant with the decline of AtR8 lncRNA levels. Moreover, increases in the levels of WRKY53 and WRKY70 mRNAs were higher in the atr8 mutant than in $\mathrm{Wt}$ and, in this case, an inverse correlation between AtR8 and WRKY53/WRKY70 was observed. These results suggest that the $A t R 8 \operatorname{lncRNA}$ functions at the early developmental stage after germination, before the onset of PR protein syntheses in germinating seeds and tiny seedlings.

A

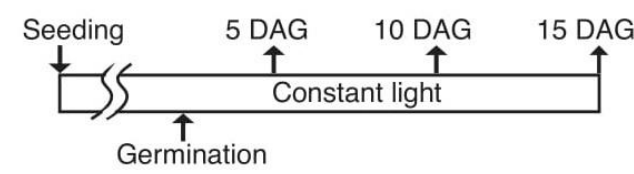

B
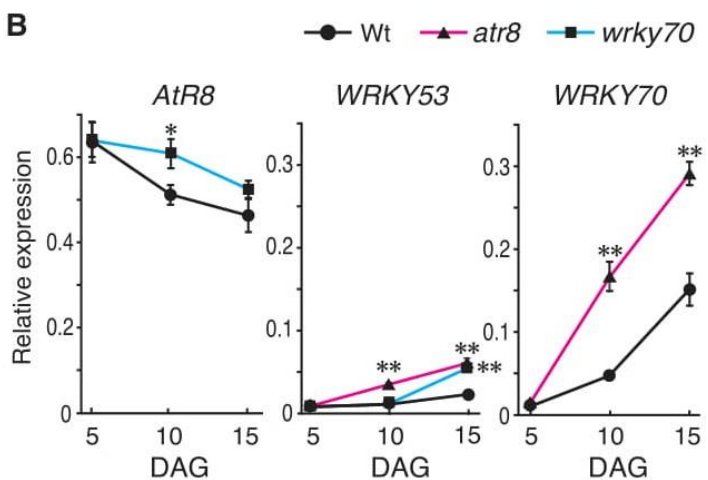

Figure 7. Time course of the RNA accumulations soon after germination. (A) Timeline of the experimental procedure. Up arrows indicate samplings. The $\mathrm{Wt}$, atr8, and wrky70 strains were germinated on $0.24 \%$ gellan gum media (without SA and P. syringae), and the total RNAs were extracted after the indicated periods (DAG: days after germination) from each strain, and subjected to RT-qPCR with ACT2 and ACT8 genes as standards. (B) Line graphs represent the mean values of three independent assays ( $\geq 60$ plants), and error bars represent \pm SE. Significant differences in RNA accumulation levels between $\mathrm{Wt}$ and each of the mutants (Wt and atr8, Wt and wrky70) are indicated as ${ }^{*} p<0.05$ and ${ }^{* *} p<0.01$ (Welch's $t$-test).

\subsection{Regulation of NPR1-Mediated Genes}

Since the AtR8 and WRKY53/WRKY70 genes are inversely and SA-dependently regulated, we further examined the contribution of NPR1 (a key regulator of SA-mediated immunity). For this purpose, we conducted RT-qPCR on an Arabidopsis hypomutant of NPR1 (npr1) to compare AtR8, WRKY53, and WRKY70 RNA accumulation at an early developmental stage (5 DAG; cf. Figure 7) in $\mathrm{Wt}$, atr8, and npr1 plants in the presence and absence of SA (Figure 8). In Wt plants, the expression of WRKY53, WRKY70, NPR1, and PR-1 mRNA was induced by SA, whereas that of AtR8 was suppressed (Figure 8B). In atr8 plants, WRKY53 and WRKY70 expression was induced by SA to a greater extent than in the $\mathrm{Wt}$, leading to the up-regulation of $P R-1$ (Figure $8 \mathrm{C}$ ). Although $n p r 1$ plants were heterozygotes, almost no NPR1 mRNA accumulation was observed; however, the levels of AtR8 lncRNA were slightly higher in these plants than in the $\mathrm{Wt}$, and the inhibitory effect of SA on AtR8 lncRNA accumulation 
was lost. In npr1 plants, PR-1 mRNA expression was not increased by SA treatment (Figure $8 \mathrm{C}$ ). These results suggest that the NPR1 might be a repressor of the AtR8 gene as well as an activator of WRKY53 and WRKY70 genes.
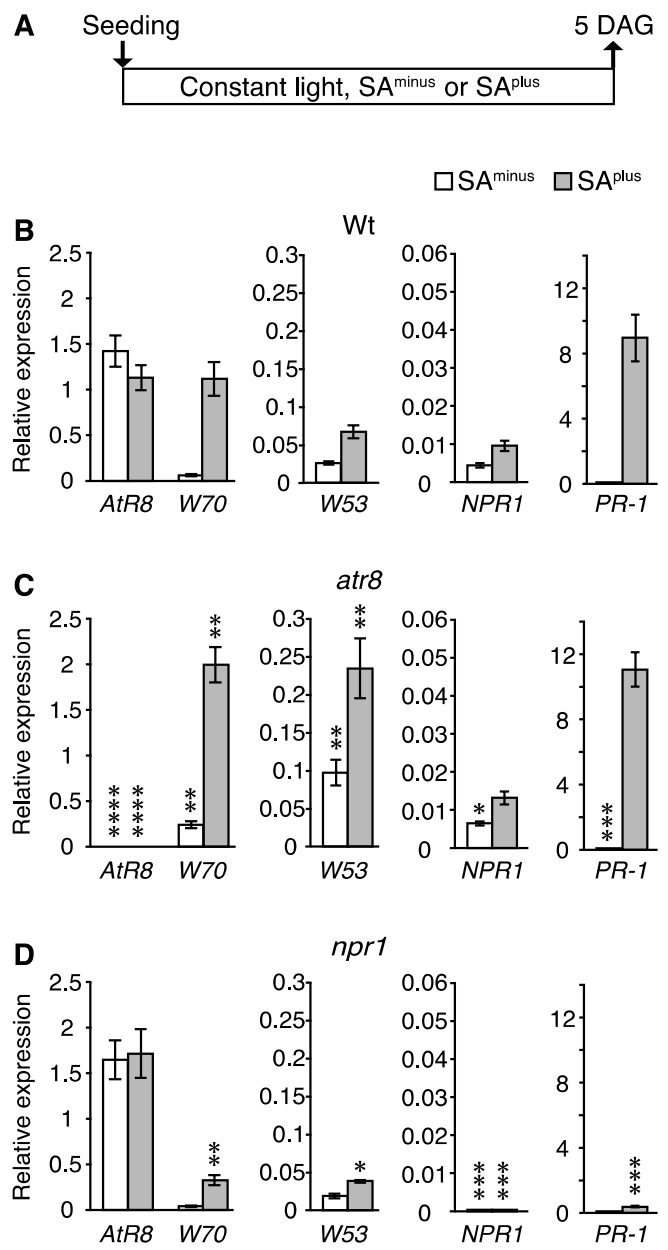

Figure 8. RNA accumulation levels in Arabidopsis plants including $n p r 1$ at an early developmental stage. (A) Timeline of experimental procedure. The total RNAs were extracted from the seedlings of $\mathrm{Wt}$, atr 8 , and $n p r 1$, which were grown on $0.24 \%$ gellan gum media SA plus or SA minus (20 $\mu \mathrm{M} \mathrm{SA})$, and subjected to RT-qPCR with ACT2 and ACT8 genes as standards. Bar graphs represent the mean values of three independent assays ( $\geq 100$ plants), and error bars represent \pm SE. W53: WRKY53, W70: WRKY70. (B) Wt, (C) atr8 (AtR8 null mutant), and (D) npr1 (NPR1 hypomutant). Significant differences in RNA accumulation levels between Wt $(\mathbf{B})$ and each of the mutants $(\mathbf{C}-\mathbf{D})$ are indicated as * $p<0.05$, ${ }^{* *} p<0.01,{ }^{* * *} p<0.001$, and ${ }^{* * * *} p<0.0001$ (Welch's $t$-test).

\section{Discussion}

\subsection{Involvement of AtR8 IncRNA in Plant Defense}

AtR8 lncRNA was previously shown to be abundantly accumulated in roots, with expression induced by hypoxic stress but suppressed by exogenous treatment with $0.5 \mathrm{mM} \mathrm{SA}$ [17]. Thus, hypoxia and defense are likely correlated with the activities of the WRKY network, and these factors interact with AtR8 lncRNA and SA in the root (also see Supplemental Figure S4).

Although lncRNA involvement with plant defense responses has not been widely reported $[8,14,45]$, ELF18-INDUCED LONG-NONCODING RNA (ELENA1) lncRNA in Arabidopsis was proposed to be pathogen responsive. Its accumulation increased 22-fold after treatment with prokaryotic elongation factor thermo unstable (EF-Tu) [46], which acts as a pathogen-associated molecular pattern, although 
this EF-Tu induction has not been confirmed in our study. Here, we provide substantial evidence for the existence of another plant defense-related lncRNA from Arabidopsis, AtR8. The first piece of evidence is provided by the microarray-based transcriptome analysis of the atr 8 mutant under hypoxic/submergence stress, in which $36 \%$ of up-regulated genes (104 of 289 genes) were associated with defense responses. WRKY genes were strongly represented in the up-regulated genes and, as reported previously, more than $70 \%$ of the WRKY gene family members are responsive to defense and SA [47].

In a previous study, we explored the potential response of AtR 8 lncRNA under stress conditions; the largest changes in AtR8 lncRNA levels were detected after waterlogging treatment [17]. Therefore, we performed a microarray-based differential accumulation analysis of $\mathrm{Wt}$ and art8 seedlings subjected to hypoxic submergence conditions, as described previously [17]. WRKYs are recognized for their roles in responding to stress and defense, but some WRKYs are also thought to contribute to the submergence response. For example, the Arabidopsis AtWRKY22 gene is involved in the regulatory networks of submergence signaling [28], while rice OsWRKY62 plays a positive role in the regulation of hypoxia-responsive genes [48]. Some aspects of the role of rice WRKYs in aerenchyma development under submergence stress were described previously [23], and Arabidopsis AtWRKY22 and rice OsWRKY62 were shown to respond to defense as well as hypoxia.

In this study, a significant association was demonstrated between accumulation of the AtR8 lncRNA and two WRKY genes (WRKY70 and WRKY53) in Arabidopsis. WRKY70 plays a key role in integrating signals from the SA and JA pathways, with WRKY70 accumulation activated by SA and repressed by JA [27]. WRKY53 is also SA-responsive and participates in plant development and defense [34,35]. Both WRKYs were also shown to act as regulators of leaf senescence [29,30,33].

The conserved WRKY domain binds preferentially to a conserved core element known as the 'W-box', which exhibits a common (T)TGAC(C/T) motif that has been observed in the promoters of multiple stress-inducible genes, including Pathogenesis-Related (PR) and WRKY genes [22,47,49,50]. Accordingly, WRKY genes can coordinate highly complex gene cascades during the defense response. In this study, we observed an inverse correlation between the expression patterns of AtR8 IncRNA and WRKY53/WRKY70 mRNA in response to SA, P. syringae infection, and early seedling development (Figure 2 and , Figures 4-7), suggesting that AtR 8 lncRNA might mutually regulate WRKY functions. Previously, several attempts were made to generate double mutants of atr 8 wrky53 and atr 8 wrky70, but the resultant heterozygotes were less likely to survive in soil, and homozygotes of these mutants were not obtained. These results suggest that such double mutants might be highly sensitive to infections and suffer from increased lethality. Importantly, AtR8 lncRNA accumulation was found to be independent of $P R-1$, because $P R-1$ mRNA levels were not changed regardless of $A t R 8$ incRNA levels in wrky53 and wrky70 (Figure 4D,E), and AtR8 IncRNA might therefore contribute to a PR-1-independent defense mechanism. This is critically different from ELENA1 lncRNA, as ELENA1 positively regulates $P R-1$ gene accumulation in cooperation with the MED19a mediator protein [46]. Moreover, although binding proteins have not yet been identified, it is likely that $A t R 8$ lncRNA forms ribonucleoproteins. Therefore, the next step will be to analyze complexes that include AtR 8 lncRNA.

\subsection{Delayed Root Elongation in atr8 Strongly Associates with SA}

Usually, mutant phenotypic characterization provides sufficient information to determine the functions of an uncharacterized gene. However, unlike protein coding genes, many ncRNA mutants do not display any clear phenotype. Previously, we reported that high levels of $A t R 8 \operatorname{lncRNA}$ accumulated in primary and lateral root apices in $\mathrm{Wt}$, but that no phenotype was found in the atr8 mutant [17]. However, careful examination of atr 8 during the course of this study revealed delayed primary root elongation in the presence of low levels of SA ( $20 \mu \mathrm{M}$; Figure 2 and Supplemental Figure S2). SA plays diverse roles during plant development and in response to stress [21], and its effect can be estimated by observing the suppression of root elongation [20]. In atr8, root elongation was more severely affected upon the application of low levels of SA. SHORT-ROOT (SHR) protein is a DNA-binding transcription 
factor that promotes root elongation during the maintenance of stem cells in RAM. Microarray analysis showed that SHR accumulation was down-regulated in atr8 (Supplemental Table S2), and RT-qPCR results indicated that $S H R$ accumulation was induced by SA in both $\mathrm{Wt}$ and atr8 plants (Figure 3). Paradoxically, SA inhibited root elongation regardless of SHR up-regulation. Furthermore, SHR induction was more pronounced in atr8. The reasons for this are not readily apparent; however, the maintenance of meristems is both complex and critical and may involve hitherto unidentified regulatory cascades. It is possible that $S H R$ gene up-regulation at least may act to counterbalance SA-induced root shortening. However, further research is needed to fully understand this relationship. Conversely, the SA-dependent inhibitory effect on root elongation was suppressed in both the wrky53 and wrky 70 mutants. Therefore, we assume that AtR 8 lncRNA negatively regulates the sensitivity of SA $(20 \mu \mathrm{M})$ on root elongation; therefore, atr8 shows a shorter root phenotype comparing with Wt. On the other hand, WRKY53 and WRKY70 positively regulate the sensitivity of SA $(20 \mu \mathrm{M})$, and longer root phenotypes appear in those mutants.

\subsection{Concentration-Dependent SA Effects}

The most intensively studied role of SA is in the plant immune response against biotrophic or hemibiotrophic pathogens. Generally, land plants have two layers of SA-induced active defense responses that help counter challenges from pathogens: (1) the hypersensitive response (HR) and (2) systemic-acquired resistance (SAR). These responses require different levels of SA induction. HR is induced by higher SA levels and causes rapid oxidative bursts and programmed cell death at the site of infection. SAR is longer lasting, persisting for several weeks, and it is induced by lower SA levels. Although the range of basal SA levels among plant species is diverse, basal SA levels in Arabidopsis are generally in the range of $0.25-1 \mu \mathrm{g} \mathrm{g}^{-1}$ fresh weight (approximately $2-7 \mu \mathrm{M}$ ), and these levels increase by a factor of at least 100 at the site of infection [51-53]. Several reports linking the exogenous application of SA to the defense response have been published, with conflicting results. Relatively high SA concentrations were used in the majority of studies. For example, using $5 \mathrm{mM} \mathrm{SA}$, Li et al. (2004) reported a gradual reduction of WRKY70 accumulation during 2-24 h after exposure [27]. $\mathrm{Hu}$ et al. (2012) reported peak WRKY70 accumulation $8 \mathrm{~h}$ after treatment with $2 \mathrm{mM} \mathrm{SA} \mathrm{[35].} \mathrm{However,}$ Shim et al. (2013) observed a gradual increase in WRKY70 accumulation for $1 \mathrm{~h}$ in response to treatment with $1 \mathrm{mM}$ SA [54]. Furthermore, $P R-1$ accumulation increased $5 \mathrm{~h}$ after treatment with $5 \mathrm{mM} \mathrm{SA} \mathrm{[27].}$ The experimental conditions in this study involved much lower SA concentrations. Root elongation in atr 8 was restricted to $20 \mu \mathrm{M}$, and opposing effects were observed in wrky70 and wrky53 mutants for the same SA concentration (Figure 2 and Supplemental Figures S1 and S2). Recently, our collaborators showed that $\mathrm{SA}(15 \mu \mathrm{M})$ was able to induce $A t R 8 \operatorname{lncRNA}$ accumulation in seeds $36 \mathrm{~h}$ after germination, whereas a lower SA concentration $(5 \mu \mathrm{M})$ was found to be inhibitory [55]. In their entirety, these results suggest that the accumulation of $A t R 8$ lncRNA responds to low SA concentrations in a very narrow concentration window $(15-20 \mu \mathrm{M})$. These results are corroborated by the inverse correlation observed between the expression patterns of AtR8 IncRNA and WRKY53/WRKY70. This also evokes the possibility of the existence of a third, as yet unknown, type of defense response involving AtR 8 lncRNA that is distinct from the HR- or SAR-type responses. The regulation of AtR8 IncRNA accumulation in a $P R$-1-independent manner supports this hypothesis (Figure 4).

\subsection{How are AtR8 and WRKY70 Expression Regulated by SA?}

As mentioned above, the accumulation of AtR 8 and WRKY53/WRKY70 transcripts correlated inversely, i.e., the deletion of one increased the expression of the other. Therefore, the next logical question is: How is this expression regulated? Here, we propose a plausible model in which NPR1 regulates the accumulation of AtR8 and WRKY53/WRKY70.

NPR1, a key regulator of basal and SAR and SA signaling in plants, confers immunity through a transcriptional cascade (which includes transcription activators and repressors), leading to a massive induction of antimicrobial gene expression. In the npr1 mutant, SA-induced transcriptional 
reprogramming, including SAR, is almost lost [26,36]. Although NPR1 cannot bind to an SA molecule directly, its paralogs (NPR3 and NPR4) are SA receptors, and they bind to SA with different affinities and regulate the ubiquitination of NPR1 [56]. In the absence of SA, oligomerized NPR1 proteins are retained in the cytoplasm, but SA-activated NPR1s are reduced together with cellular redox changes, monomerized, and translocated to the nucleus. Monomeric NPR1 does not exhibit DNA-binding activity as a TF; instead, it regulates target genes by interacting with a wide range of transcription activators, repressors, and cofactors that include members of the WRKY and bZIP transcription factor TGA families as well as NIM1-interacting proteins (NIMINs) [57,58]. NPR1 was proposed to regulate the transcription of $P R$ genes together with the TGA family TF as a cofactor [59]. Numerous previous studies showed that NPR1 up-regulated WRKY70 accumulation in an SA-dependent manner $[27,60]$. How is AtR8 and WRKY70/WRKY53 accumulation regulated inversely? To answer this question, we hypothesize an NPR1-mediated model. First, the NPR1/TGA complex could bind to WRKY genes on the $\mathrm{W}$-box and to the AtR8 gene; this is because $\mathrm{W}$-box-like sequences reside in their $5^{\prime}$ proximal regions. Second, we think that NPR1/TGA might regulate those genes inversely. To evaluate this hypothesis, we generated NPR1 mutants (npr1) (Figure 8). At an early growing stage (5 DAG; cf. Figure 7), a defect in the NPR1 gene (npr1) contributed to the accumulation of AtR8 IncRNA, regardless of the SA conditions, thereby confirming this theory. By contrast, deregulation of NPR1 in the npr1 mutant plant does not require the de novo production of accessory proteins and can thus proceed. Even though the proposed mechanism seems feasible, further investigations into the mechanism underlying the NPR1-mediated regulation of AtR8 lncRNA are required for confirmation.

\subsection{Biological Implications of the Involvement of AtR8 IncRNA in the Defense Response}

Although AtR8 $\operatorname{lncRNA}$ accumulates predominantly in the roots, it was recently shown to also accumulate in germinating seeds [55]. One of the common keywords that links roots and seeds is 'soil'. As many plant diseases originate in the soil, plants are constantly required to select alternative strategies based on a 'growth-defense trade-off' [61,62]. For germinating seeds, growth should be prioritized over other physiological processes, but investments in defense are also essential to neutralize the challenges posed by surrounding pathogens. However, because resources are limited within the relatively small Arabidopsis seed, an optimal defense response that is frugal in energy consumption would be preferred at this stage. HR and SAR are highly evolved and finely tuned systems, but their immense metabolic cost would undoubtedly be disadvantageous for fragile seedlings in their early stages of development. Our data suggest that an additional primitive, energy-efficient, defense mechanism involving Atr 8 lncRNA may be present.

If this kind of defense mechanism exists, the participation of reactive oxygen species (ROS) might not be negligible, because several pieces of collateral evidence link AtR 8 lncRNA to ROS production. $A t R 8$ lncRNA accumulation in Wt seeds was enhanced upon the application of SA [55]. In general, SA induces the production of ROS during seed germination, and ROS play a key role during seed germination and protection against pathogens [63,64]. As ROS can be generated in mitochondria, chloroplasts, or peroxisomes in the cytoplasm, the localization of AtR8 lncRNAs in the cytoplasm correlates well with the site of ROS production. Interestingly, the accumulation of many mitochondriaand chloroplast-related genes was also significantly down-regulated in atr8 mutants (Supplemental Table S3). As roots are the first point of contact with the microbial community in the soil, defense-related proteins are constitutively expressed in roots $[65,66]$. However, an AtR8-based defense mechanism could be operative during the early stages of root development to tilt the balance in favor of an energy trade-off. Our data clearly demonstrate that atr 8 mutation causes suppressed root elongation, while wrky70 and wrky53 mutation resulted in enhanced root elongation. In parallel, the proposed PR-1-independent defense mechanism might be suppressed in the atr 8 mutant but enhanced in the wrky70 and wrky53 mutants. 
Under low SA concentrations, deletion of the WRKY53 gene did not affect WRKY70 accumulation; however, the loss of WRKY70 did affect WRKY53 gene accumulation (Figures 4 and 5), suggesting that WRKY70 may act upstream of WRKY53 in a WRKY cascade (Figure 9).

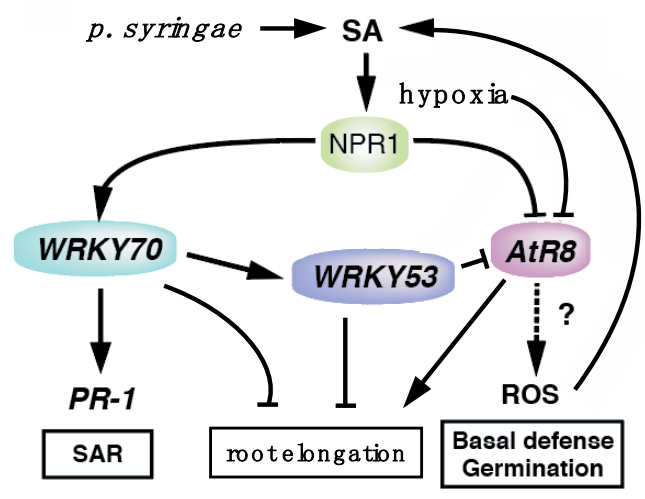

Figure 9. Proposal working model that illustrates the interaction among the AtR8 long non-coding RNA (lncRNA) and WRKY network with SA-dependent defense signaling. AtR8 lncRNA might regulate the basal defense system independent from SAR. The AtR8 lncRNA potentially exhibits an inverse correlation to the WRKY70 gene with SA-dependent defense signaling and root elongation. WRKY70 is upstream in the WRKY signaling cascade, while AtR8 lncRNA is repressed by WRKY53. The NPR1 might be a key regulator for mutual regulation between AtR 8 lncRNA and WRKY70 genes.

In conclusion, the data presented in this paper strongly suggest the involvement of AtR8 IncRNA in a defense response that also involves WRKY70/WRKY53 (Figure 9). At a minimum, the defense mechanism operates in the roots and at the early stages of seed germination. Further studies are required to elucidate the mechanistic details underlying this response.

\section{Materials and Methods}

\subsection{Plant Materials and Growth Conditions}

Arabidopsis thaliana (L.) Heynh. accession Wassilevskija (WS) and AtR8 lncRNA-defective mutant FLAG-410H04, designated atr8 (derived from WS by T-DNA insertion), were obtained from the Versailles Arabidopsis Stock Center (the National Institute for Agricultural Research, Versailles, France, http://publiclines.versailles.inra.fr/). T-DNA insertion mutants wrky53 (SALK_034157c), wrky70 (SALK_025198c), and npr1 (SALK_204100c) (derived from Arabidopsis accession Columbia) were obtained from The Arabidopsis Biological Resource Center (ABRC, the Ohio State University, Clumbus, $\mathrm{OH}, \mathrm{USA}$, https://abrc.osu.edu/). All mutants (except for npr1) used in this study harbor null alleles. Mutants were characterized by PCR and RT-qPCR. Double mutants atr8 wrky53 and atr 8 wrky70 were obtained by crossing atr 8 with wrky 53 or wrky70, respectively. Arabidopsis plants were maintained under a $16 \mathrm{~h}$ light (approximately $60 \mu \mathrm{mol} \mathrm{m}{ }^{-2 \mathrm{~s}}$ )/8 h dark cycle at $20^{\circ} \mathrm{C}$. Seedlings were grown on soil or on half-strength $\left(\frac{1}{2}\right)$ Murashige and Skoog (MS) medium supplemented with $2 \%(w / v)$ sucrose, $0.5 \mu \mathrm{g} \mathrm{mL}{ }^{-1}$ thiamine-HCl, $0.2 \mathrm{mM}$ phosphate buffer $\mathrm{pH} 6.6$, and $0.24 \%(w / v)$ or $0.4 \%(w / v)$ gellan gum.

\subsection{Transcription Analysis of atr8 Mutant}

Wild-type (Wt) and atr8 seedlings (10 DAG) were dipped in air-purged water for $6 \mathrm{~h}$ (hypoxic stress treatment) and then placed in fresh $\frac{1}{2}$ MS agar medium for recovery. Total RNA was extracted using Tripure Isolation Reagent (Roche Life Science, Penzberg, Germany) $22 \mathrm{~h}$ after the recovery treatment. Total RNA was used for microarray analysis using an Affymetrix ATH1 Arabidopsis expression array.

Total RNA (up to $500 \mathrm{ng}$ ) isolated from atr8 and Wt seedlings (10 DAG) was amplified and labeled using a 3' IVT Express kit (Affymetrix, Santa Clara, CA, USA). The target preparation, hybridization, 
washing, staining, and scanning of array chips were carried out in accordance with manufacturer protocols. Affymetrix GeneChip Command Console ${ }^{\circledR} 3.0$ (AGCC) software was used to control the washing and staining of array chips in a Fluidics Station 450 (Affymetrix) as well as scanning with a Scanner 3300 (Affymetrix). Three biological replicates, processed at each stage of microarray analysis and with overall correlation coefficient values of $\geq 0.95$, were used for final data analysis. Differential expression analyses for mutant lines were performed on quantile-normalized datasets with a fold change cut-off $=2$ at $p \leq 0.05$ using the CLC Main Workbench 7.8.1 (CLC Bio, Aarhus, Denmark, https://www.qiagenbioinformatics.com/) software package. Microarray data are deposited in the Gene Expression Omnibus database (NCBI, Bethesda, MD, USA).

\subsection{Gene Expression Analysis}

Total RNA was extracted from whole seedlings using Tripure Isolation Reagent. Reverse transcription quantitative PCR (RT-qPCR) was performed using a One-Step SYBR PrimeScript RT-PCR Plus Kit (Takara Bio) and the Eco Real-Time PCR System (Illumina) in $10 \mu \mathrm{L}$ reactions containing $50 \mathrm{ng}$ or $100 \mathrm{ng}$ of total RNA. Reverse transcription was carried out at $42{ }^{\circ} \mathrm{C}$ for $5 \mathrm{~min}$, followed by 40 cycles at $95{ }^{\circ} \mathrm{C}$ for $5 \mathrm{~s}$ and $60^{\circ} \mathrm{C}$ for $30 \mathrm{~s}$. A comparative quantitation was carried out via the $2^{(-\Delta \mathrm{Ct})}$ method or $2^{(-\Delta \Delta C t)}$ method [67]. Each amplified fragment was validated by electrophoresis and by sequencing. The primers used for RT-PCR are listed in Supplemental Table S1.

For northern analysis, the RNA probe template, plasmid YA41-R8, was constructed using a genomic PCR fragment containing the AtR 8 lncRNA transcribed region, which was amplified with the following primers: 5' CGG TCT AGA GGG GTG TGG GAA CCT AGG AGA 3' (forward) and $5^{\prime}$ ATT GGA TCC GAG GAA ACG GTT AAC CGC AGA 3' (reverse). Total RNA from seedlings $(5 \mu \mathrm{g})$ was separated on a $6 \%(w / v)$ polyacrylamide gel $(7 \mathrm{M}$ urea, $1 \times$ Tris-Borate-EDTA (TBE) buffer) and transferred onto a nylon membrane (Hybond-N, GE Healthcare). After UV cross-linking and pre-hybridization with DIG Easy Hyb (Roche Life Science), the membrane was hybridized overnight at $45^{\circ} \mathrm{C}$ with a $1 \mu \mathrm{g} / \mathrm{mL}$ DIG-labeled riboprobe in DIG Easy Hyb. The membrane was washed twice with $2 \times$ Saline-Sodium-Citrate (SSC) buffer/0.1\% (w/v) SDS at room temperature followed by washing with $0.2 \times \mathrm{SSC} / 0.1 \%(w / v)$ SDS at $42{ }^{\circ} \mathrm{C}$. After blocking with $1.5 \%(w / v)$ blocking reagent (Roche Life Science) and treatment with anti-DIG Alkaline Phosphatase (AP)-conjugated antibody (1:10,000, Roche Life Science), the blots were detected using CDP-star (Roche Life Science) using Hyper film ECL (GE Healthcare).

\subsection{Salicylic Acid Treatment}

Seedlings from $\mathrm{Wt}$ as well as atr8, wrky53, and wrky70 mutants were germinated on a horizontal plane of $\frac{1}{2}$ MS medium with $0.24 \%(w / v)$ gellan gum, with or without $20 \mu \mathrm{M} \mathrm{SA}$. At $10 \mathrm{DAG}$, seedlings were transplanted onto a vertical plane of $\frac{1}{2}$ MS medium with $0.4 \%(w / v)$ gellan gum, with or without $20 \mu \mathrm{m} \mathrm{SA}$, and grown for 10 more days. The length of the primary root was measured using the ImageJ [68] software package.

Time-course experiments for SA treatment were performed as follows: seedlings ( $\mathrm{Wt}$, atr8, wrky53, and wrky70) were grown on $\frac{1}{2}$ MS medium with $0.24 \%(w / v)$ gellan gum for 2 weeks, dipped in $20 \mu \mathrm{M}$ SA solution (or water as a control), and returned to fresh $\frac{1}{2}$ MS medium with $(20 \mu \mathrm{M})$ or without SA (control). Total RNA was extracted 0, 0.5, 1, 6, and $24 \mathrm{~h}$ after SA treatment.

\subsection{Infection with Pseudomonas Syringae}

Arabidopsis seedlings were infected with the plant pathogen Pseudomonas syringae pv. tagetis (P. syringae) as follows: P. syringae was streaked and cultured on King's agar medium for 2 days at room temperature and then cultured overnight at $37^{\circ} \mathrm{C}$ in King's liquid medium. An aliquot $(500 \mu \mathrm{L})$ of culture was centrifuged, and the bacterial pellet was suspended in $50 \mathrm{~mL}$ sterile water to generate a pathogen suspension. Two-week-old seedlings grown on $\frac{1}{2}$ MS medium with $0.24 \%(w / v)$ gellan gum were dipped in pathogen suspension and then placed onto a fresh $\frac{1}{2}$ MS plate. Seedlings were 
harvested $0,0.5,1,6$, and $24 \mathrm{~h}$ after infection, and total RNA was extracted from 10 seedlings at each time point.

Supplementary Materials: The following are available online at http://www.mdpi.com/2311-553X/6/1/8/s1, Figure S1. Inhibitory effects of root elongation under different SA conditions; Figure S2. Inhibitory effects of root elongation with $20 \mu \mathrm{M}$ SA condition; Figure S3. Short-term time course of RNA levels induced by infection with Pseudomonas syringae; Figure S4. Expression levels of RNAs in Arabidopsis roots under continuous treatment with $20 \mu \mathrm{M}$ SA. Table S1. List of primers using RT-qPCR in this study; Table S2. Microarray analysis data obtained from wild-type and atr8 plants; Table S3. Hyper geometrical classification of microarray data; Table S4. Ranking of down- and up-regulated gene classification in atr8 by GO Slim Term; Table S5. Heat maps of Go Slim Term categorization in atr8; Table S6. List of major stress and defense related genes largely changed in atr8 plant.

Author Contributions: S.L., Y.Y. and J.W. designed the research. S.L. and S.N. performed the research. S.L., S.K., H.J. and Y.Y. analyzed the data. S.L., Y.Y., S.N. and S.K. wrote the article. All authors have read and agreed to the published version of the manuscript.

Funding: This work was supported by the Joint Research Project between Japan and India (2012-2013) within the Bilateral Program between the Japan Society for the Promotion of Science (JSPS) and the Indian Department of Science \& Technology (DST) (JUTAK82402 to Y.Y. and JUTAK82503 to S.K.), as well as JSPS KAKENHI grant JP19K06711 (to Y.Y.). The authors would also like to thank the Nittoku Asian Student Scholarship Foundation and the Yokoyama International Scholarship Foundation for financial support (to S.L.).

Acknowledgments: The authors would like to thank Prof. M. Sugiura for generous support, and Ms. M. Yukawa for fruitful technical discussions. Moreover, the authors acknowledge the assistance of the Research Equipment Sharing Center at Nagoya City University.

Conflicts of Interest: The authors declare no conflict of interest.

\section{References}

1. Consortium, E.P. An integrated encyclopedia of DNA elements in the human genome. Nature 2012, 489, 57-74. [CrossRef]

2. Hon, C.C.; Ramilowski, J.A.; Harshbarger, J.; Bertin, N.; Rackham, O.J.; Gough, J.; Denisenko, E.; Schmeier, S.; Poulsen, T.M.; Severin, J.; et al. An atlas of human long non-coding RNAs with accurate $5^{\prime}$ ends. Nature 2017, 543, 199-204. [CrossRef] [PubMed]

3. Jin, J.; Liu, J.; Wang, H.; Wong, L.; Chua, N.H. PLncDB: Plant long non-coding RNA database. Bioinformatics 2013, 29, 1068-1071. [CrossRef] [PubMed]

4. Amor, B.; Wirth, S.; Merchan, F.; Laporte, P.; d'Aubenton-Carafa, Y.; Hirsch, J.; Maizel, A.; Mallory, A.; Lucas, A.; Deragon, J.; et al. Novel long non-protein coding RNAs involved in Arabidopsis differentiation and stress responses. Genome Res. 2009, 19, 57-69. [CrossRef] [PubMed]

5. Zhu, Q.; Stephen, S.; Taylor, J.; Helliwell, C.A.; Wang, M. Long noncoding RNAs responsive to Fusarium oxysporum infection in Arabidopsis thaliana. New Phytol. 2014, 201, 574-584. [CrossRef]

6. Cui, J.; Luan, Y.; Jiang, N.; Bao, H.; Meng, J. Comparative transcriptome analysis between resistant and susceptible tomato allows the identification of lncRNA16397 conferring resistance to Phytophthora infestans by co-expressing glutaredoxin. Plant. J. 2017, 89, 577-589. [CrossRef]

7. Xin, M.; Wang, Y.; Yao, Y.; Song, N.; Hu, Z.; Qin, D.; Xie, C.; Peng, H.; Ni, Z.; Sun, Q. Identification and characterization of wheat long non-protein coding RNAs responsive to powdery mildew infection and heat stress by using microarray analysis and SBS sequencing. BMC Plant. Biol. 2011, 11, 61. [CrossRef] [PubMed]

8. Liu, J.; Jung, C.; Xu, J.; Wang, H.; Deng, S.; Bernad, L.; Arenas-Huertero, C.; Chua, N.-H. Genome-Wide Analysis Uncovers Regulation of Long Intergenic Noncoding RNAs in Arabidopsis. Plant. Cell 2012, 24, 4333-4345. [CrossRef]

9. Ma, J.; Bai, X.; Luo, W.; Feng, Y.; Shao, X.; Bai, Q.; Sun, S.; Long, Q.; Wan, D. Genome-Wide Identification of Long Noncoding RNAs and Their Responses to Salt Stress in Two Closely Related Poplars. Front. Gen. 2019, 10, 777. [CrossRef]

10. Wang, A.; Hu, J.; Gao, C.; Chen, G.; Wang, B.; Lin, C.; Song, L.; Ding, Y.; Zhou, G. Genome-wide analysis of long non-coding RNAs unveils the regulatory roles in the heat tolerance of Chinese cabbage (Brassica rapa ssp.chinensis). Sci. Rep. 2019, 9, 5002. [CrossRef]

11. Chekanova, J.A. Long non-coding RNAs and their functions in plants. Curr. Opin. Plant. Biol. 2015, 27, 207-216. [CrossRef] [PubMed] 
12. Liu, J.; Wang, H.; Chua, N. Long noncoding RNA transcriptome of plants. Plant. Biotechnol. J. 2015, 13, 319-328. [CrossRef] [PubMed]

13. Shafiq, S.; Li, J.; Sun, Q. Functions of plants long non-coding RNAs. Bioch. Biophys. Acta 2016, 1859, $155-162$. [CrossRef] [PubMed]

14. Wang, J.; Meng, X.; Dobrovolskaya, O.B.; Orlov, Y.L.; Chen, M. Non-coding RNAs and Their Roles in Stress Response in Plants. Genom. Proteom. Bioinform. 2017, 15, 301-312. [CrossRef] [PubMed]

15. Yu, T.; Zhu, H. Long Non-Coding RNAs: Rising Regulators of Plant Reproductive Development. Agronomy 2019, 9, 53. [CrossRef]

16. Böhmdorfer, G.; Sethuraman, S.; Rowley, J.M.; Krzyszton, M.; Rothi, H.M.; Bouzit, L.; Wierzbicki, A.T. Long non-coding RNA produced by RNA polymerase V determines boundaries of heterochromatin. Elife 2016, 5, e19092. [CrossRef]

17. Wu, J.; Okada, T.; Fukushima, T.; Tsudzuki, T.; Sugiura, M.; Yukawa, Y. A novel hypoxic stress-responsive long non-coding RNA transcribed by RNA polymerase III in Arabidopsis. RNA Biol. 2012, 9, 302-313. [CrossRef]

18. Wu, J.; Liu, C.; Liu, Z.; Li, S.; Li, D.; Liu, S.; Huang, X.; Liu, S.; and Yukawa, Y. Pol III-dependent cabbage BoNR8 long ncRNA affects seed germination and growth in Arabidopsis. Plant. Cell Physiol. 2018, 10, 1093. [CrossRef]

19. Röhrig, H.; Schmidt, J.; Miklashevichs, E.; Schell, J.; John, M. Soybean ENOD40 encodes two peptides that bind to sucrose synthase. Proc. National Acad. Sci. USA 2002, 99, 1915-1920. [CrossRef]

20. Steenackers, W.J.; Cesarino, I.; Klíma, P.; Quareshy, M.; Vanholme, R.; Corneillie, S.; Kumpf, R.P.; Van De Wouwer, D.; Ljung, K.; Goeminne, G.; et al. The Allelochemical MDCA Inhibits Lignification and Affects Auxin Homeostasis. Plant Physiol. 2016, 172, 874-888. [CrossRef]

21. Rivas-San Vicente, M.; Plasencia, J. Salicylic acid beyond defence: Its role in plant growth and development. J. Exp. Bot. 2011, 62, 3321-3338. [CrossRef]

22. Rushton, P.J.; Somssich, I.E.; Ringler, P.; Shen, Q.J. WRKY transcription factors. Trends Plant. Sci. 2010, 15, 247-258. [CrossRef] [PubMed]

23. Viana, V.E.; Busanello, C.; da Maia, L.C.; Pegoraro, C.; Costa de Oliveira, A. Activation of rice WRKY transcription factors: An army of stress fighting soldiers? Curr. Opin. Plant. Biol. 2018, 45, 268-275. [CrossRef] [PubMed]

24. Chen, L.; Song, Y.; Li, S.; Zhang, L.; Zou, C.; Yu, D. The role of WRKY transcription factors in plant abiotic stresses. Bioch. Biophys. Acta 2012, 1819, 120-128. [CrossRef] [PubMed]

25. Li, J.; Brader, G.; Kariola, T.; Palva, T.E. WRKY70 modulates the selection of signaling pathways in plant defense. Plant. J. 2006, 46, 477-491. [CrossRef] [PubMed]

26. Wang, D.; Amornsiripanitch, N.; Dong, X. A Genomic Approach to Identify Regulatory Nodes in the Transcriptional Network of Systemic Acquired Resistance in Plants. Plos. Pathog. 2006, 2, e123. [CrossRef] [PubMed]

27. Li, J.; Brader, G.; Palva, T.E. The WRKY70 Transcription Factor: A Node of Convergence for Jasmonate-Mediated and Salicylate-Mediated Signals in Plant Defense. Plant. Cell 2004, 16, 319-331. [CrossRef]

28. Hsu, F.C.; Chou, M.Y.; Chou, S.J.; Li, Y.R.; Peng, H.P.; Shih, M.C. Submergence confers immunity mediated by the WRKY22 transcription factor in Arabidopsis. Plant. Cell 2013, 25, 2699-2713. [CrossRef]

29. Besseau, S.; Li, J.; Palva, T.E. WRKY54 and WRKY70 co-operate as negative regulators of leaf senescence in Arabidopsis thaliana. J. Exp. Bot. 2012, 63, 2667-2679. [CrossRef]

30. Ulker, B.; Shahid Mukhtar, M.; Somssich, I.E. The WRKY70 transcription factor of Arabidopsis influences both the plant senescence and defense signaling pathways. Planta 2007, 226, 125-137. [CrossRef]

31. Brusslan, J.A.; Alvarez-Canterbury, A.M.; Nair, N.; Rice, J.C.; Hitchler, M.J.; Pellegrini, M. Genome-Wide Evaluation of Histone Methylation Changes Associated with Leaf Senescence in Arabidopsis. PLoS ONE 2012, 7, e33151. [CrossRef] [PubMed]

32. Lin, J.; Wu, S. Molecular events in senescing Arabidopsis leaves. Plant. J. 2004, 39, 612-628. [CrossRef] [PubMed]

33. Miao, Y.; Laun, T.; Zimmermann, P.; Zentgraf, U. Targets of the WRKY53 transcription factor and its role during leaf senescence in Arabidopsis. Plant. Mol. Biol. 2004, 55, 853-867. [CrossRef] [PubMed] 
34. Xie, Y.; Huhn, K.; Brandt, R.; Potschin, M.; Bieker, S.; Straub, D. REVOLUTA and WRKY53 connect early and late leaf development in Arabidopsis. Development 2014, 141, 4772-4783. [CrossRef] [PubMed]

35. Hu, Y.; Dong, Q.; Yu, D. Arabidopsis WRKY46 coordinates with WRKY70 and WRKY53 in basal resistance against pathogen Pseudomonas syringae. Plant. Sci 2012, 185-186, 288-297. [CrossRef] [PubMed]

36. Cao, H.; Glazebrook, J.; Clarke, J.D.; Volko, S.; Dong, X. The Arabidopsis NPR1 Gene That Controls Systemic Acquired Resistance Encodes a Novel Protein Containing Ankyrin Repeats. Cell 1997, 88, 57-63. [CrossRef]

37. Berardini, T.; Mundodi, S.; Reiser, L.; Huala, E.; García-Hernández, M.; Zhang, P.; Mueller, L.A.; Yoon, J.; Doyle, A.; Lander, G.C.; et al. Functional Annotation of the Arabidopsis Genome Using Controlled Vocabularies1. Plant Physiol. 2004, 135, 745-755. [CrossRef]

38. Gu, Y.; Zavaliev, R.; Dong, X. Membrane Trafficking in Plant Immunity. Mol. Plant. 2017, 10, 1026-1034. [CrossRef]

39. Bacete, L.; Mélida, H.; Miedes, E.; Molina, A. Plant cell wall-mediated immunity: Cell wall changes trigger disease resistance responses. Plant J. Cell Mol. Biol. 2017, 93, 614-636. [CrossRef]

40. Benfey, P.N.; Linstead, P.J.; Roberts, K.; Schiefelbein, J.W.; Hauser, M.T.; Aeschbacher, R.A. Root development in Arabidopsis: Four mutants with dramatically altered root morphogenesis. Development 1993, 1, 57-70.

41. Ji, W.C.; Jun, L. Control of Asymmetric Cell Divisions during root ground tissue maturation. Mol. Cells 2016, 7, 524-529.

42. Levesque, M.P.; Vernoux, T.; Busch, W.; Cui, H.; Wang, J.Y.; Blilou, I.; Hassan, H.; Nakajima, K.; Matsumoto, N.; Lohmann, J.U.; et al. Whole-Genome Analysis of the SHORT-ROOT Developmental Pathway in Arabidopsis. Plos. Biol. 2006, 4, e143.

43. Dhondt, S.; Coppens, F.; Winter, F.; Swarup, K.; Merks, R.M.; Inzé, D.; Bennett, M.J.; Beemster, G.T. SHORT-ROOT and SCARECROW Regulate Leaf Growth in Arabidopsis by Stimulating S-Phase Progression of the Cell Cycle. Plant. Physiol. 2010, 154, 1183-1195. [CrossRef] [PubMed]

44. Long, Y.; Stahl, Y.; Weidtkamp-Peters, S.; Postma, M.; Zhou, W.; Goedhart, J.; Sánchez-Pérez, M.-I.; Gadella, T.W.; Simon, R.; Scheres, B.; et al. In vivo FRET-FLIM reveals cell-type-specific protein interactions in Arabidopsis roots. Nature 2017, 548, 97-102. [CrossRef] [PubMed]

45. Lakhotia, S.C. Long non-coding RNAs coordinate cellular responses to stress. Wiley Interdiscip. Rev. RNA 2012, 3, 779-796. [CrossRef]

46. Seo, J.; Sun, H.-X.; Park, B.; Huang, C.-H.; Yeh, S.-D.; Jung, C.; Chua, N.-H. ELF18-Induced Long-Noncoding RNA Associates with Mediator to Enhance Expression of Innate Immune Response Genes in Arabidopsis. Plant. Cell 2017, 29, 1024-1038. [CrossRef]

47. Dong, J.; Chen, C.; Chen, Z. Expression profiles of the Arabidopsis WRKY gene superfamily during plant defense response. Plant. Mol. Biol. 2003, 51, 21-37. [CrossRef]

48. Fukushima, S.; Mori, M.; Sugano, S.; Takatsuji, H. Transcription Factor WRKY62 Plays a Role in Pathogen Defense and Hypoxia-Responsive Gene Expression in Rice. Plant. Cell Physiol. 2016, 57, 2541-2551. [CrossRef]

49. Eulgem, T.; Somssich, I.E. Networks of WRKY transcription factors in defense signaling. Curr. Opin. Plant. Biol. 2007, 10, 366-371. [CrossRef]

50. Chi, Y.; Yang, Y.; Zhou, Y.; Zhou, J.; Fan, B.; Yu, J.-Q.; Chen, Z. Protein-protein interactions in the regulation of WRKY transcription factors. Mol. Plant. 2013, 6, 287-300. [CrossRef]

51. Brodersen, P.; Malinovsky, F.; Hématy, K.; Newman, M.-A.; Mundy, J. The Role of Salicylic Acid in the Induction of Cell Death in Arabidopsis acd11. Plant. Physiol. 2005, 138, 1037-1045. [CrossRef] [PubMed]

52. Nawrath, C.; Métraux, J.-P. Salicylic Acid Induction-Deficient Mutants of Arabidopsis Express PR-2 and PR-5 and Accumulate High Levels of Camalexin after Pathogen Inoculation. Plant. Cell 1999, 11, 1393-1404. [PubMed]

53. Wildermuth, M.C.; Dewdney, J.; Wu, G.; Ausubel, F.M. Isochorismate synthase is required to synthesize salicylic acid for plant defence. Nature 2001, 414, 562-565. [CrossRef] [PubMed]

54. Shim, J.S.; Jung, C.; Lee, S.; Min, K.; Lee, Y.-W.; Choi, Y.; Lee, J.S.; Song, J.T.; Kim, J.-K.; Choi, Y.D. AtMYB44 regulates WRKY70 expression and modulates antagonistic interaction between salicylic acid and jasmonic acid signaling. Plant J. 2012, 73, 483-495. [CrossRef] [PubMed]

55. Li, D.; Huang, X.; Liu, Z.; Li, S.; Okada, T.; Yukawa, Y.; Wu, J. Effect of AtR8 lncRNA partial deletion on Arabidopsis seed germination. Mol. Soil Biol. 2016, 7, 1-7. [CrossRef]

56. Fu, Z.; Yan, S.; Saleh, A.; Wang, W.; Ruble, J.; Oka, N.; Mohan, R.; Spoel, S.H.; Tada, Y.; Zheng, N.; et al. NPR3 and NPR4 are receptors for the immune signal salicylic acid in plants. Nature 2012, 486, 228-232. [CrossRef] 
57. Qi, G.; Chen, J.; Chang, M.; Chen, H.; Hall, K.; Korin, J.; Liu, F.; Wang, D.; Fu, Z. Pandemonium Breaks Out: Disruption of Salicylic Acid-Mediated Defense by Plant Pathogens. Mol. Plant. 2018, 11, 1427-1439. [CrossRef]

58. Sun, Y.; Detchemendy, T.; Pajerowska-Mukhtar, K.; Mukhtar, M.S. NPR1 in JazzSet with Pathogen Effectors. Trends Plant. Sci. 2018, 23, 469-472. [CrossRef]

59. Fan, W.; Dong, X. In Vivo Interaction between NPR1 and Transcription Factor TGA2 Leads to Salicylic Acid-Mediated Gene Activation in Arabidopsis. Plant Cell Online 2002, 14, 1377-1389. [CrossRef]

60. Ren, C.-M.; Zhu, Q.; Gao, B.-D.; Ke, S.-Y.; Yu, W.-C.; Xie, D.-X.; Peng, W. Transcription factor WRKY70 displays important but no indispensable roles in jasmonate and salicylic acid signaling. J. Integr. Plant. Biol. 2008, 50, 630-637. [CrossRef]

61. Huot, B.; Yao, J.; Montgomery, B.L.; He, S. Growth-Defense Tradeoffs in Plants: A Balancing Act to Optimize Fitness. Mol. Plant. 2014, 7, 1267-1287. [CrossRef] [PubMed]

62. Smakowska, E.; Kong, J.; Busch, W.; Belkhadi, Y. Organ-specific regulation of growth-defense tradeoffs by plants. Curr. Opin. Plant. Biol. 2016, 29, 129-137. [CrossRef] [PubMed]

63. El-Maarouf-Bouteau, H.; Bailly, C. Oxidative signaling in seed germination and dormancy. Plant. Signal. Behav. 2008, 3, 175-182. [CrossRef] [PubMed]

64. Leymarie, J.; Vitkauskaité, G.; Hoang, H.; Gendreau, E.; Chazoule, V.; Meimoun, P.; Corbineau, F.; El-Maarouf-Bouteau, H.; Bailly, C. Role of Reactive Oxygen Species in the Regulation of Arabidopsis Seed Dormancy. Plant. Cell Physiol. 2012, 53, 96-106. [CrossRef]

65. De-la-Peña, C.; Badri, D.V.; Lei, Z.; Watson, B.S.; Brandão, M.M.; Silva-Filho, M.C.; Sumner, L.W.; Vivanco, J.M. Root Secretion of Defense-related Proteins Is Development-dependent and Correlated with Flowering Time. J. Biol. Chem. 2010, 285, 30654-30665. [CrossRef]

66. Coninck, B.; Timmermans, P.; Vos, C.; Cammue, B.P.; Kazan, K. What lies beneath: Belowground defense strategies in plants. Trends Plant. Sci. 2015, 20, 91-101. [CrossRef]

67. Schmittgen, T.D.; Livak, K.J. Analyzing real-time PCR data by the comparative CT method. Nat. Protoc. 2008, 3, 1101-1108. [CrossRef]

68. Schindelin, J.; Rueden, C.T.; Hiner, M.C.; Eliceiri, K.W. The ImageJ ecosystem: An open platform for biomedical image analysis. Mol. Reprod. Dev. 2015, 82, 518-529. [CrossRef] 